When makerspaces go mobile: case studies of transportable maker locations

By: Heather M. Moorefield-Lang

Moorefield-Lang, H.M. (2015). When makerspaces go mobile: Case studies of transportable maker locations. Library Hi Tech, 33(4). 462-471.

Made available courtesy of Emerald Publishing Limited: https://doi.org/10.1108/LHT-062015-0061

\begin{abstract}
***(C) Emerald Publishing Limited. Reprinted with permission. No further reproduction is authorized without written permission from Emerald Publishing Limited. This version of the document is not the version of record. Figures and/or pictures may be missing from this format of the document. ***
\end{abstract}

\author{
Abstract: \\ Purpose \\ - The purpose of this paper is to describe the implementation of mobile makerspaces in libraries \\ and educational settings. Insights, decisions, challenges, and mobile makerspace projects will \\ also be shared. \\ Design/methodology/approach \\ - This paper delves into six case studies of librarians and educators who made the decision to go \\ mobile with a makerspace. The case studies include public and school librarians, as well as \\ educators in higher education settings. The author of this paper will describe the cases, projects, \\ challenges, along with other aspects of implementing of a mobile makerspace. \\ Findings \\ - Makerspaces, while becoming very popular in the field of librarianship, can be incredibly \\ exciting to employ but often come with their own challenges and successes. What happens when \\ the brick and mortar location is not enough? Librarians and educators begin to think creatively \\ and bring the makerspace to the patrons if the clients cannot come to the space. \\ Originality/value \\ - Currently the research on makerspaces is growing but there is still a limit to scholarly material \\ in this field. When focussing on mobile makerspaces there are only blog posts and popular \\ pieces. Nothing has been written on a wider range of case studies focussing on mobile \\ makerspaces. This paper sets the foundation for further exploration in how librarians and \\ educators can further serve patrons by making makerspaces mobile.
}

Keywords: Libraries | Case studies | Qualitative research | Makerspaces | Mobile makerspaces

Article:

Introduction 
Makerspaces continue to increase in popularity in library settings around the world. Librarians in public, school, as well as university settings have begun to incorporate these learning spaces and maker technologies in their libraries during the last two years. Maker learning spaces are seen as a new way to provide service, a space where knowledge and content can be created. Libraries in the past have been seen as locations where information was absorbed, not created, and makerspaces change that.

While makerspaces are still new and exciting, what happens when clients, patrons, and students cannot travel to the makerspace? What should be decided for those schools that do not have a budget for a makerspace? What can be implemented for the branch libraries that do not have room for a maker location? These are only some of the questions that inspired librarians and educators to make makerspaces mobile.

Makerspaces are sites where students and patrons can produce, craft, solve problems, collaborate and develop new skills (Preddy, 2013). They are locations where users can learn through experimentation and play. Makerspaces are places where users can gather, share, and explore (Britton, 2012). No makerspace is the same. The same definitions and rules apply to mobile makerspaces. Mobile makerspaces are simply maker locations that can move. For the purposes of this research mobility means any makerspace that leaves the original premises. Some mobile makerspaces travel for a day at a time, others for a week, while some are mobile all year long.

In this paper six different mobile makerspaces will be shared, with locations around the world. As with fixed makerspaces, no two are the same. Each makerspace provides a different set of skills, classes, and experiences to their patrons and students. At the core their impetus is very similar. Provide outstanding learning opportunities to young people, library clients, and consumers no matter where they are located. If they cannot, or would not, come to us, we will go to them.

\section{Review of literature}

The research on makerspaces continues to grow but there remains a limit to scholarly and peerreviewed research in this field. When focussing on mobile makerspaces there are solely blog posts and pieces in popular publications. Nothing has been written on a wider range of case studies that focus on mobile makerspaces. Maker learning spaces in library and most educational settings are still emerging and the idea of making going mobile is a very novel concept.

The foundation for library-based mobile makerspaces resides within the bookmobile. The earliest book wagon made its way through Washington County, Maryland in 1905. Its purpose to provide library services to patrons who might not have them in their area (Goldstein, 1961). Bookmobiles increased exponentially after Second World War. They could move from locations and provide services to patrons no matter where they were located (Smith, 1961). While the items being delivered have changed from books to technology, the foundational belief behind the bookmobile transfers directly to the ideal of the mobile makerspace. Take the maker location and the making activities to the patrons. If the patron cannot or would not come to the library maker area, the makerspace can come to them. Providing good service and materials for clients no 
matter where they may be located continues to be the focus for going mobile for over a hundred years.

Lim Peng Han (2010) traces the history of a multilingual public library system in Singapore from 1956-1991 part of which includes a mobile children's service. Two branch librarians based out of local community centers in Singapore visit 2,000 children in 35 rural schools every two weeks during 1960. By the end of the year over 4,500 students were being served who previously had no access to books or to the opportunity for home reading. Han (2010) includes the expansion and the decentralization of the library services in Singapore in this piece. Discussing the importance of these mobile services, especially to young patrons in rustic locations.

In his white paper, “Think like a start up,” Brian Mathews (2012) discusses how libraries can better support twenty-first century learners. Libraries no longer fill their dictionary definition; librarians must stretch out past any perceived limitations and evolve. Librarians can work in spaces not recognized as a typical library location to provide better assistance and aid patrons in their needs. Library faculty and staff also need to think differently or outside of the box. Specifically he recommends that they think like innovators which is in line of the mode of thinking needed for makerspaces. Going mobile takes the already innovative idea of makerspaces even further.

In a comparative case study of three makerspaces Sheridan, et al. (2014) looks at makerspaces and how these learning spaces function as environments for learning. Delving into research questions that focus on participants, tools, processes, methods, and learning in makerspaces Sheridan and co-authors look at the similarities and differences across three makerspace sites. Participants varied depending on the focus of the makerspace as did the projects and focus in making ideas. As noted previously each makerspace is different but they share a foundational belief in making and creating. It does not matter where the maker learning space is located, whether it is fixed or mobile, creativity, innovation, and creation continue to be the foci of these locations.

Peltonen and Wickstrom (2014) discuss their makerspace in the Tapiola Library. Created in summer 2013, the researchers were curious about mobile technologies and learning for young people. Moving from projects with iPads, tablet computers, and other handheld devices, the evolution to a maker learning space made sense. In their article, “3D-prints and robots play a part in my story. Participatory learning action and content creation in a library makerspace”, Peltonen and Wickstrom share projects and ideas that took place in their library's makerspace. Scavenger hunts, robots, photo journaling of fun things to do in the library, and garage band ringtone workshops are only some of the events that took place. In the future computer programming and coding workshops are planned, as well as projects revolving around literature.

Christina Echegaray (2015) discusses the mobile makerspace at Vanderbilt University for their Monroe Carell Jr Children's Hospital. This mobile maker center arrives on a cart to the patient's room with bins full of circuits, LED lights, wires, and more. The mobile makerspace has a 3D printer and has been made available to the young people at the Children's Hospital so that they might be involved in rich learning activities. Young patients can create anything they want with 
this mobile makerspace, it takes their minds off of what is happening in the hospital while also offering engaging learning opportunities.

It does not matter if library services are being delivered by wagon, car, cart, or bus. Nor if the books are being brought to young people on a burro as Luis Soriano has done in Magdalena, Colombia (Ruffins, 2010). Going mobile is an opportunity to bring library and educational services to students, patrons, and clients no matter where they are located. While the look and feel of libraries may change in the coming years, the core foundation remains the same, find out the needs of the patrons and meet them.

\section{Methodology}

This paper reports the cases of six in-depth interviews with librarians and educators who made the decision to go mobile with a makerspace. Librarians and educators in the K-12 school, public, and university sectors have been included for a better representation of mobile makerspaces and their implementation. Names of librarians, educators, and their makerspaces are shared in this paper as explained and accepted through internal review board documentation and approval for this research. A convenience sampling was used for this research, speaking with the librarians and educators who volunteered and had mobile makerspaces. Mobile makerspaces defined as any maker location that left the brick and mortar location where it was originally housed. Two makerspaces were in fully built trucks, one was carried in a library van, two makerspaces were transported in school buses, and one traveled across campus in a cart. Interviews were conducted via Skype online chat service, Google Hangout, or phone. All interviews were audio-recorded and transcribed verbatim. Participants knew from the recruitment protocol that focus of the interviews was based on their mobile makerspaces, technologies, implementation, challenges, and projects. The first two questions always asked were, "What is the name of your mobile makerspace? Where is it housed when it is not on the road?” From there participants received questions on their makerspaces, places they had traveled, implementation decisions, training techniques, funding, challenges and successes with the technology and space, patron reactions, as well as favorite projects and ideas.

\section{Case studies}

\section{Makers on the Move, Monticello High School, Charlottesville, Virginia, USA}

We decided to go mobile for a couple of reasons. We get so full here (in the library space) so providing projects and ideas and space and interesting things for all of the kids to do is challenging. Sending them out to do projects with other classes provides them that outlet of creativity. It also helps to develop social skills. Going out to other places and interacting with strangers is good practice for them in developing their speaking and presentation skills (Ida Mae Craddock, Librarian, Monticello High School).

Monticello High School and its librarians are well known for their makerspace. This public high school in Charlottesville, Virginia had a makerspace for over two years in their library and the maker mentality has completely taken root in the school. Visitors will find maker activities occurring in the school halls, classrooms, and the library. The makerspace is fully integrated. 
While the makerspace at Monticello is successful, other schools in the Charlottesville school system are not as fortunate to have these opportunities. Craddock and her students decided to do something to rectify that situation. By creating a program they call "Makers on the Move" once a week, on Thursday afternoons, Mae Craddock and her high school students visit their younger peers at the nearby elementary and middle schools to engage in maker activities. Taking such technologies as a 3D printer to the middle school and technologies to take-apart for projects, to date activities include computer coding and programming, 3D printing, take-apart technology, and a myriad of artistic activities. The program has been a success and reactions have been overwhelmingly positive.

This particular group uses a bus to take the students from their high school to the neighboring elementary and middle schools. Most technology used in the maker activities is provided by Monticello High School as is the bus and gasoline. Fortunately the partnering elementary school recently received a $3 \mathrm{D}$ printer though, grant funding which means one less piece of technology to convey. The success of the program far outweigh any challenges. High school students are gaining teaching and outreach opportunities, while their younger counterparts are receiving maker experiences they never had before. An example of how school partnerships can be successful as well as how mobile making can aid students at all levels.

\section{Frysklab Mobile Fablab, Friesland, Netherlands}

That's the beautiful thing about being on wheels, we get to take the FabLab to these great places, meet all of these beautiful people. It's wonderful (Jeroen de Boer, Project Leader, Frysklab).

Europe's first mobile library fablab, called Frysklab, comes out of Friesland in the Northern part of the Netherlands. FryskLab is an initiative of the provincial public library service organization, Bibliotheekservice Fryslân. This service began two years ago in September, 2013. The staff decided to go mobile because of the rural location of their province. With so many small villages in the area making the fablab mobile made the most sense. This way the Frysklab staff could visit schools, neighboring provinces, and other countries if desired. In fact in February, 2015 Frysklab designed a MakerTour 2015 that included twelve stops in eight different countries across Europe including such locations as Florence, Italy and Cologne, Germany.

The Frysklab is a fully operational fablab complete with all types of technologies for making, some of which include 3D printers, vinyl cutters, laptops, and Makey-Makey Invention kits. With each stop they offer experiences for patrons with 3D printing, laser and vinyl cutting, as well as programming. They are specifically a fablab and not a makerspace because of the strong international FabLab network and its knowledge exchange capacities. The staff of the Frysklab also has a sustainability emphasis and their own titled workshop named Frysklab Elements. Each element has its own product. For example in the workshop for Wind patrons will create wind monsters, small robots that blow in the breeze. For the earth workshop participants will print with clay. In a Water session young people will create their own water cannon. The employees of this mobile fablab wish to focus on the local environment and how making, creating, and original ideas can turn back to the current world's situations. 
The reactions to the Frysklab Mobile Fablab have been affirmative. Those patrons, young people, students, and adults who have experienced it come with questions and are amazed by the possibilities. Friesland was the first location in the Netherlands to have a bookmobile and they are carrying on the tradition by going mobile with a fablab.

\section{Mini Makerlab, Chicago Public Library, Chicago, Illinois, USA}

Due to us having the MakerLab out in these locations we have seen people who went to the Mini MakerLab now coming downtown because now it's worth the trip. Before it was like, well that would be nice but I've got all this other stuff to do but now we have people who have come in. It's like any other city, you do things in your neighborhood, you shop there, you go to your branch, and you don't travel downtown unless you have to (Mark Anderson, Librarian, Chicago Public Library).

The Chicago Public Library main branch in downtown Chicago is already well known for their makerspace which opened in July, 2013. A year later the library staff realized that not all patrons were being reached and the decision was made to go mobile during the summer of 2014 by creating a Mini MakerLab. As patrons came to their standalone makerspace in the downtown branch staff members were collecting data during classes and maker sessions, one of the items of data being collected was zip codes and this information helped them to determine where the Mini MakerLab should travel.

During summer, 2014 the Mini Makerlab was established in three separate library branches across the Chicago area for six weeks at a time. Each Makerlab included two 3D printers, two vinyl cutters, an e-textile kit for knitting, and other assorted craft supplies. Using a van to take the materials to each branch, the technology stays at the branch library during the six week Mini Makerlab. The main library also provided a staff member to aid the branch librarians, as well as funding for each branch to invite local artists or presenters to take part in each individual makerspace as well as the community's area of focus.

The program has been very successful. For the upcoming summer, in 2015, the Chicago Downtown Branch posted a call to all other branches to see who would like to have the Mini MakerLab for the summer. They decided to go by request instead of location or area zip codes. Based on the list of volunteers the staff has chosen three new libraries for the summer and each MakerLab will take place for eight weeks. A staff member from the main branch will once again be available to aid local branch librarians and this year the library is posting a board in each individual library to see what types of maker classes or activities should be offered.

\section{MobileMaker, Elon University, Elon, North Carolina, USA}

We want to broaden and open our minds to different ways we could be writing and we see a real opportunity to do that. It's not just about pen and papers, typing an essay, write on a keyboard. It's actually the thought process and the trial and error that goes into how we put together code for programming, a particular piece on a rocket (Dana Gierdowski, Senior Program Coordinator for the Writing Excellence Initiative, Elon University). 
On the campus of Elon University in Elon, North Carolina is the MobileMaker, a rolling cart for making very similar to the cart created for young hospital patients at Vanderbilt University (Echegaray, 2015). Born from a Writing Excellence Initiative for the Elon community, the MobileMaker is a year old. This maker cart is typically housed in one of the residential halls on campus but with its mobility it can be moved to any desired location. During the interviews for this research the MobileMaker was residing in the university library for writing center purposes.

Within the MobileMaker resides a myriad of technology and software for making. The maker cart contains a 3D printer and scanners, an invention kit called Makey-Makey, Little Bits electronic kits, conductive electric paint, a vinyl and paper cutter, Arduino microcontrollers, as well as books and software for making and creating. Since this is a rolling cart it is easy to imagine that weight plays a factor in its mobility so while the MobileMaker can move locations it does tend to stay in one place for a period of time.

This particular mobile making station is designed to help make writing more visible across campus in all of its various forms, hence students use it to create as well as write. For instance engineer students will create a project with the MobileMaker and then write or blog about their making experience. The idea behind this particular project was always for students to write or blog after using the MobileMaker. To see making as part of the creative process, it is just like writing. It is just a different way of writing, way to think through the creative and creation process.

\section{DHMakerBus, London, Ontario, Canada}

Most times, even when we're working with kids, we come out learning something from them, as opposed to just us teaching and it being taught down. We learn from them as much as they learn from us (Beth Compton, Team Member, DH Makerbus).

In London, Ontario is Canada’s first mobile makerspace titled DHMakerBus, the DH for digital humanities. During the low snow months the DHMakerBus travels in a converted school bus but when snow makes bus travel difficult DHMaker activities continue by car or truck throughout the London area. Going into their third year, this mobile maker bus has mainly traveled in their local London area but like the previously discussed Frysklab and the following mobile maker lab SparkTruck they have plans for cross-country maker experiences with the DHMakerBus.

The MakerBus comes complete with a variety of technology and craft based tools for making. GoPro cameras, a 3D printer, and a drone Arducopter start the list of their impressive technologies. The staff of the DHMakerBus also has a button press machine, a Sphero Robot ball, Google Cardboard kits, as well as MakeDos which are plastic components and gears which allow patrons to invent and create elaborate structures with the MakeDo pieces and cardboard.

Most of the DHMakerBus visits are what would be defined as pop-ups, one day activity or professional development visits. The entire project started with public library partnerships and has continued as such over the past three years. DHMakerBus has expanded into professional development for teachers and librarians as well in their area. The feedback for DHMaker has 
been incredibly positive and the DHMakerBus team has found that people love school buses and the ways that it can be used especially when it comes to the world of making.

\section{SparkTruck, Stanford University, Palo Alto, California, USA}

The educators and other grown-ups with whom we interact always report how powerful it is to see their kids so engaged in our activities and enjoying what they're doing. It helps convey the idea that student engagement, getting students to be really present and enjoy what they're doing, is a really powerful way to get them to learn more deeply, and to get them to care about what their learning (Eugene Korsunskiy, Co-Founder, SparkTruck).

SparkTruck is defined on their web site as an educational build-mobile. A project that began in a rental truck in February, 2012 soon became a nation-wide maker experience. Managed by the d.school at Stanford University, the SparkTruck was one of the first mobile makerspaces in the USA. This team has traveled across the USA offering pop-up maker opportunities at libraries, schools, community centers, and more. They have also paved the way for peer mobile makers by creating a How to Make a SparkTruck Guide and documenting their cross-country road trips.

The SparkTruck is a vehicle full of technology. Some of their offerings include a Cube 3D printer, a laser cutter and vinyl cutter, and four iPads. For building and creating the SparkTruck also has scissors, hammers, glue guns, and a polymer clay oven. Some of the popular projects created with the SparkTruck staff have been vibrobots which are small vibrating robots that run on a small battery and motor as well as stamp creation using the laser cutter.

The SparkTruck visits are also considered pop-ups, one day visits where set up and break down all happen in the same day, similar to the DHMakerBus from Canada and the Frysklab in the Netherlands. The SparkTruck travels to locations where they have been invited by teachers, librarians, and community members. The reaction to the SparkTruck has been incredibly positive with educators, librarians, and school administrators recognizing a love of learning and exploration from their students not often seen in traditional classrooms. An incredibly exciting journey for all involved.

\section{Discussion}

Makerspaces in libraries and education offer new opportunities for students and patrons in the areas learning and creativity. These learning locations can also provide possibilities for problem solving, model creation, investigation and exploration, data analysis, solution design, and overall STEM inquiry (Science, Technology, Engineering, and Mathematics) (Peppler et al., 2015). Makerspaces can be located in a permanent location, they can move within a library or school, or they can go on the road. Each librarian and educator interviewed during this research study discussed their decision for making the makerspace mobile. These makerspaces has many common issues when it came to implementation or challenges, funding, as well as training.

\section{Challenges}


Unfortunately it seems to be growing in popularity. They are now getting more calls which necessitate transportation. We are currently struggling with growth (Ida Mae Craddock, Librarian, Monticello High School).

Everything new comes with challenges and implementing a new project like a mobile makerspaces will certainly come with its own trials. Demand is always a challenge. Like all makerspaces, when the word gets out students, patrons, and the public in general are going to want to see what this mobile makerspace or fablab is all about. This is a good problem to have. Other challenges will arrive with the mode of transportation. Buses, cars, trucks, and vans all require gasoline and petrol, and that requires funding, which will be discussed in the following section. Vehicles also require maintenance, insurance, and if students and children under 18 are riding or using your vehicle further considerations are required. Other thoughts for mobile makerspace implementation involve where to travel, how often, and what types of technologies and materials will be on or with the mobile maker learning space. Early and ongoing planning was involved with each represented mobile makerspace in this research study.

\section{Funding}

We had, you know, when we opened the funding from the IMLS grant, and then we received a grant from the Motorola Mobility Fund. And that is going to carry us through the end of this year and then we don't know yet. Not sure who to go after next (Mark Anderson, Librarian, Chicago Public Library).

The librarians and educators of the mobile makerspaces who took part in this study gained funding for their makerspaces in full or partially with grants. Other monies were gained through donations of funds or goods, Indiegogo, Kickstarter, foundational funding, or other types of fundraising. Going forward into future years these mobile makerspaces will continue to pursue funding through many of the same means looking at such grants as those given by the Institute of Museum and Library Services.

\section{Training}

We're all self-taught. Pretty much anything that we bring into the bus project is something that we learn really quickly in order to teach it largely, too (Kimberley Martin, Team Member, DH Makerbus).

No training whatsoever, seeing what happens, self-taught, peer training, and trial and error were common terms among the case study participants when it came to the discussion of training for their mobile makerspaces. Some librarians or educators had found peers in local museums, schools, or departments for aid when questions arose. Others found that social media was helpful for posting questions and gaining quick answers. Many people who worked on mobile makerspaces rarely worked alone so problem solving, finding answers, and learning for new technologies and skills became a team effort. Makerspaces are locations for collaborative learning and those who work in them have to be ready to learn with the students as well as be ready to fail with the students. 


\section{Conclusion}

Makerspaces are considered informal learning locations where the creative arts, technologies, and science can come together for idea exploration, product creation, problem solving, and collaboration (Sheridan, et al., 2014). These spaces can open the door to opportunities in learning, innovation, creation, and investigation. When patrons and students cannot come to existing makerspaces in a brick and mortar setting, offering a mobile option meets a service based need. Mobile makerspaces provide exploration, innovation, and collaboration opportunities to patrons and students anywhere, further serving and advancing the role of the library and school outside of their walls.

\section{References}

1. Britton, L. (2012), “The makings of maker spaces, part 1: space for creation, not just consumption”, Library Journal , Vol. 15 No. 2, pp. 85-108, available at: www.thedigitalshift.com/2012/10/public-services/the-makings-of-maker-spaces-part-1-spacefor-creation-not-just-consumption/ (accessed April 15, 2015). [Google Scholar] [Infotrieve]

2. Echegaray, C. (2015), “Mobile makerspaces provides patients tools to create, inspire”, available at: http://news.vanderbilt.edu/2015/02/mobile-makerspace-provides-patients-tools-tocreate-inspire/ (accessed April 4, 2015). [Google Scholar]

3. Goldstein, H. (Ed.) (1961), “Introduction”, Library Trends: Current Trends in Book Mobiles , University of Illinois Graduate School of Library Science, Urbana, IL, pp. 287-290. [Google Scholar]

4. Han, L.P. (2010), "The history of an emerging multilingual public library system and the role of mobile libraries in post colonial Singapore, 1956-1991”, Malaysian Journal of Library and Information Science, Vol. 15 No. 2, pp. 85-108. [ISI], [Google Scholar] [Infotrieve]

5. Mathews, B. (2012), “Think like a startup: a white paper to inspire library entrepreneurialism”, available at: http://vtechworks.lib.vt.edu/handle/10919/18649 (accessed June 20, 2015). [Google Scholar]

6. Peltonen, M. and Wickstrom, M. (2014), “3D-prints and robots play a part in my story. Participatory learning action and content creation in a library maker space”, available at: http://library.ifla.org/869/1/120-peltonen-en.pdf (accessed June 23, 2015). [Google Scholar]

7. Peppler, K. , Maltese, A. and Kuene, A. (2015), “Open portfolios maker education initiative: Survey of makerspaces, part 2”, available at: http://makered.org/open-portfolios-survey-ofmakerspaces-part-ii/ (accessed May 5, 2015). [Google Scholar]

8. Preddy, L.B. (2013), School Library Makerspaces: Grades 6-12 , Libraries Unlimited, Santa Barbara, CA. [Google Scholar] 
9. Ruffins, E. (2010), “Teaching kids to read from the back of a burro”, available at: www.cnn.com/2010/LIVING/02/25/cnnheroes.soriano/ (accessed June 20, 2015). [Google $\underline{\text { Scholar] }}$

10. Sheridan, K.M. , Halverson, E.R. , Litts, B.K. , Brahms, L. , Jacobs-Priebe, L. and Owens, T. (2014), "Learning in the making: a comparative case study of three makerspaces", Harvard Educational Review , Vol. 84 No. 4, pp. 505-531. [Crossref], [ISI], [Google Scholar] [Infotrieve]

11. Smith, S.W. (1961), "Potentials and capabilities of bookmobiles for library service”, in Goldstein, H. (Ed.), Library Trends: Current Trends in Book Mobiles , University of Illinois Graduate School of Library Science, Urbana, IL, pp. 296-302. [Google Scholar]

\begin{abstract}
About the author
Heather Michele Moorefield-Lang is an Assistant Professor at the University of South Carolina in the School of Library and Information Science. She received her Masters in Library Science from the University of North Carolina at Greensboro and her Doctorate in Education from the University of North Carolina at Chapel Hill. Her research is focussed in emerging technologies and how they are used in education and libraries. Her current research focusses on makerspaces and their subsequent technologies in libraries of all types and levels. To learn more about Heather and her work, see her web site www.techfifteen.com or follow her on Twitter @actinginthelib. Heather Michele Moorefield-Lang can be contacted at: hmoorefield@gmail.com
\end{abstract}

